\title{
Porous Ceramics Membrane Preparation from Ternary Mixtures of Ranong Kaolin, Calcium Carbonate and Silica
}

\author{
B. Darunee ${ }^{1^{*}}$, C. Nucharee ${ }^{2} \&$ B. Tripob ${ }^{3}$ \\ 1.:2 Material Science Program, ${ }^{*}$ Membrane Science Technology Research Center, Faculty of Science, \\ Prince of Songkla University (PSU), Songklla 90112,Thailand \\ ${ }^{3}$ Department of Physics, Prince of Songkla University 90112 , Thailand
}

\begin{abstract}
Porous ceramics membranes were prepared from ternary mixtures of Ranong kaolin, calcium carbonate and silica using slip casting technique. Totally 10 different composition mixtures were selected from the ternary diagram of $\mathrm{CaCO}_{3}: \mathrm{SiO}_{2}$ : Clay with weight fraction of $0-0.19: 0.28-0.47: 0.52-0.71$, respectively. The cerarnic paste was first fired at $800^{\circ} \mathrm{C}$ and then sintered at temperatures of 1200,1250 and $1300^{\circ} \mathrm{C}$. The results show that firing temperature above $1200^{\circ} \mathrm{C}$ is probably too high to prepare the porous ceramics of the studied compositions. The porosity less than $26 \%$ is obtained from the samples sintered at $1250-1300^{\circ} \mathrm{C}$. The highest porosities of more than $40 \%$ are observed from the samples sintered at $1200^{\circ} \mathrm{C}$ with the weight fraction of clay, calcium carbonate and silica between $0.524-0.562,0.076-0.152$, and $0.310-0.394$, respectively. In this range of compositions, the linear shrinkage and water absorption is about $3 \%$ and $22 \%$, respectively, while the bending strength is between $28-30 \mathrm{MPa}$. The pure water flux of samples prepared from mixture formula 9 sintered at $1200^{\circ} \mathrm{C}$ ranges between 52.4 and 368.8 $\mathrm{L} / \mathrm{m}^{2} . \mathrm{h}$ at the operating pressures $30-120 \mathrm{kPa}$, indicating that the mixture compositions nearby the formula 9 are the best for porous ceramic production using Ranong kaolin.
\end{abstract}

Keywords: Porous ceramics membrane, Ranong kaolin, calcium carbonate, silica, slip casting, temary diagram

\subsection{INTRODUCTION}

The porous ceramics have been used for a long time for thermal insulation purpose as building materials. Uses of ceramics membranes in separation processes have rapidly increased during the last 15 years. Applications of porous ceramic as filters, catalyst supports and membranes are rapidly growing in the fields of environment, chemistry, biotechnology, foods processing and wastewater treatment.

Porous ceramics have been produced by several methods [1-3]. A common method is the polymeric sponge method [4] which involves the impregnation of polymeric sponge into slurries containing

\footnotetext{
* Corresponding author: B. Darunee (email: darunee.b@psu. ac.tin)
}

particles and appropriate binders followed by drying and sintering. Clay minerals have wellknown structural adsorption, rheological and thermal properties [5, 6]. Studies of porous membranes prepared entirely from natural clay have just started [7-9]. Cost is an important factor to be considered in view of industrial production. Clay is a natural raw material that is cheap and rich in nature. Ceramic products of natural clay have been widely used in our life. However, there are only a few investigations dealing with clay porous ceramic, although these cheap products are highly desired in environmental protection process, such as cleaning wastewater and filtering hot gas. Membrane processes have increasingly been employed in a number of industrially important operations that encompass a wide variety of operating conditions. The use of 
membrane technology to replace a separation or purification step that is part of an existing industrial process may reduce the overall consumption of energy and producc acceptable results under milder conditions.

In addition, inorganic membranes offer several advantages over their organic ones, such as good thermal and chemical resistance and better mechanical strength. Consequently, a great deal of research has been devoted in recent years.to the development of new types of inorganic membranes, which include zeolites, carbon and porous ceramic oxides. In contrast, the fabrication of inorganic membranes in which the major component is a naturally occurring clay mineral is a novel approach that has received only limited attention in the literature. Le Van Mao and coworkers studied the composite membranes prepared using sepiolite clay as a binder [8]. More recently, Shukla and Kumar used the zeolite clay composite membranes for separation of chloride salts of trivalent cations [9]. The preparation of inorganic membranes composed entirely of a naturally occurring clay mineral is an area of research that remains virtually unexplored. The development of clay-based inorganic membranes could lead to an important new technological application that would add economic value to the vast natural deposits of clay minerals that are located throughout the world, many of which are currently under utilized.

In ceramic mixtures, there are generally three major components (ternary mixtures) to be considered in ceramic processing: a plastic component (clay), an inert component (usually quartz) and a fluxing component (usually feldspar). Thus, a ternary diagram can be used to represent the composition of any such ceramic mixture and a property axis and property value can then be plotted, perpendicular to the triangle plane, or contoured over the ternary diagram, to represent the technological properties of the ceramic ternary mixtures.

This work describes the design of ternary ceramic mixture experiments methodology to obtain the experimental results relating the technological properties of interests of ceramic bodies, with the proportions of ternary composition, i.e., clay, quartz and calcium carbonate, under constant processing conditions. The ternary diagrams representing the technological properties obtained can then be used to sclcct the best combination of those three raw materials to produce a ceramic product with specified properties, for example a porous ceramic in which the properties of interest are the porosity, water absorption and bending strength.

\subsection{EXPERIMENTAL PROCEDURE}

The raw materials for ternary mixtures used were Ranong kaolin from Rathnarathorn mine (commercial grade), calcium carbonate (Merck, Germany) and silica sand (99.29 wt.\% quartz). The simplex-axial design was used to define the mixtures of those raw materials to be investigated. Each selected nixture was wet grinding for 24 hour, aging for 1 day, and preparing 15 disc-shaped samples by the slip casting method. The samples were then oven-dried at $110^{\circ} \mathrm{C}$ until constant weight, biscuit fired at $800^{\circ} \mathrm{C}$ for 1 hour (heating at $4^{\circ} \mathrm{C} / \mathrm{min}$ up to $800^{\circ} \mathrm{C}$ ), and sintering at 1200 , 1250 and $1300^{\circ} \mathrm{C}$ for $1 \mathrm{~h}$ (heating at $4^{\circ} \mathrm{C} / \mathrm{min}$ up to $600^{\circ} \mathrm{C}$, and at $4^{\circ} \mathrm{C} / \mathrm{min}$ from 600 to $1200-$ $1300^{\circ} \mathrm{C}$ ), and naturally cooled.

The linear shrinkage was determined according to the standard method ASTM C326 [10], upon firing, of the tested samples. Water absorption and related properties were determined following the standard method ASTM C373-88 (2006) [11]. For each mixture, the average property value was taken from five samples tested. Those values were then used to calculate and draw the contour line of the properties of interests in the ternary diagram. The pose size of the product ceramic membrane was determined using the method of mercury intrusion porosimetry (Quantachrome Instruments, Model PoreMaster, USA). The pore/surface morphology was examined using a scanning electron microscope (JEOL, Model JSM-5800VL, Japan).

\subsection{RESULTS AND DISCUSSION}

\subsection{Simplex Axial Design of Ternary Mixtures}

Totally 10 mixture clay-calcium carbonate-silica sand compositions were prepared from the simplex 
Table 1 Ten mixtures designed from the simplex axial ternary compositions showing individual component weight in gram. The total weight of each mixture is fixed at 105 gram. The number in blanket is weight fractions.

\begin{tabular}{cccc}
\hline Mixture & silica (g) & $\mathrm{CaCO}_{3}(\mathrm{~g})$ & Clay (g) \\
\hline 1 & $30(0.29)$ & $0(0.00)$ & $75(0.71)$ \\
2 & $40(0.38)$ & $0(0.00)$ & $65(0.62)$ \\
3 & $50(0.48)$ & $0(0.00)$ & $55(0.52)$ \\
4 & $33(0.31)$ & $3(0.03)$ & $69(0.66)$ \\
5 & $44(0.42)$ & $3(0.03)$ & $58(0.55)$ \\
6 & $36.67(0.35)$ & $6.67(0.06)$ & $61.67(0.59)$ \\
7 & $30(0.29)$ & $10(0.09)$ & $65(0.62)$ \\
8 & $40(0.38)$ & $10(0.09)$ & $55(0.52)$ \\
9 & $33(0.31)$ & $14(0.13)$ & $58(0.55)$ \\
10 & $30(0.29)$ & $20(0.19)$ & $55(0.52)$
\end{tabular}

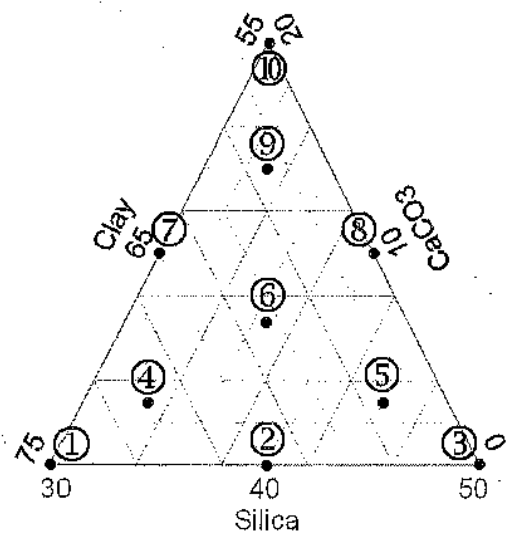

axial mixture design. The ternary mixture composition, clay, silica sand and the calcium carbonate content in gram represented a point inside the ternary diagram (Table 1 ). Table 1 showed the compositions of those 10 mixtures in terms of the independent components, and the average values $(n=5)$ for linear firing shrinkage, porosity, water absorption and strength of rupture of the tested samples were shown in Table 2 .

\subsection{Contour Plots}

Table 2 shows the results of the experiments. The important properties shown in Table 2 include the linear firing shrinlkage, porosity, water absorption and bending strength. Those properties are obtained after firing the tested samples at 1200 , 1250 and $1300^{\circ} \mathrm{C}$. Data from this table are gridded and contoured using Surfer software (Golden Software, USA) and shown in Figures 1 - 5, which show the projection of the selected property onto the composition triangle, as constant property contours. Figure 1 shows the contour plots for the linear firing shrinkage at different firing temperatures. It can be seen that the firing shrinkage increases from the minimum $2,4 \%$ (mixture formula 9 at $1200^{\circ} \mathrm{C}$; Figure 1 (a)) to the maximum $22.4 \%$ (mixture formula 3 at $1300^{\circ} \mathrm{C}$; Figure 1 (c)) when the firing temperature increases from 1200 to $1300^{\circ} \mathrm{C}$. The clay has the strongest effect on the linear shrinkage, followed by the quartz. Figure 2 shows the contour plots for the porosity at different

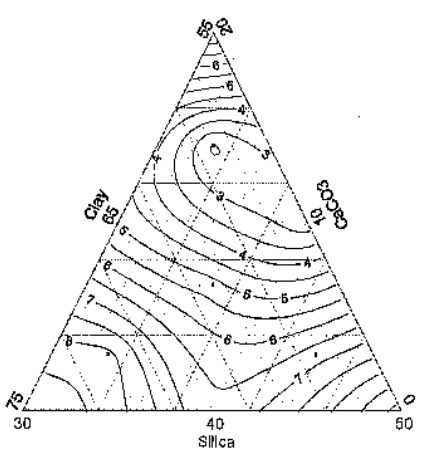

(a) $1200^{\circ} \mathrm{C}$

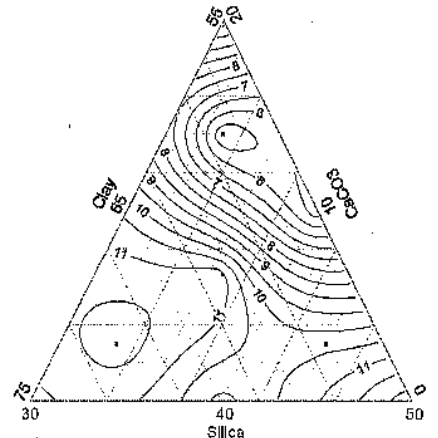

(b) $1250^{\circ} \mathrm{C}$

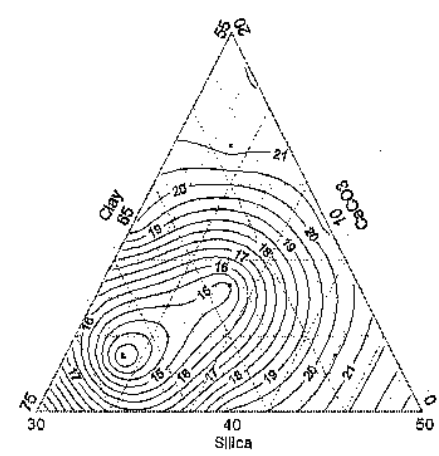

(c) $1300^{\circ} \mathrm{C}$

Figure 1 Average firing shrinkage (\%) after firing at temperatures (a) 1200 , (b) 1250 and (c) $1300^{\circ} \mathrm{C}$ 
Table 2 The selected properties of the tested samples of ceramic membrane prepared from 10 mixtures at different firing temperatures

\begin{tabular}{|c|c|c|c|c|c|c|c|c|c|c|c|c|}
\hline \multirow{2}{*}{$\begin{array}{l}\text { Mixture } \\
\text { formula }\end{array}$} & \multicolumn{3}{|c|}{ Linear shrinkage (\%) } & \multicolumn{3}{|c|}{ Porosity (\%) } & \multicolumn{3}{|c|}{ Water absorption (\%) } & \multicolumn{3}{|c|}{ Bending strength (MPa) } \\
\hline & $1200^{\circ} \mathrm{C}$ & $1250^{\circ} \mathrm{C}$ & $1300^{\circ} \mathrm{C}$ & $1200^{\circ} \mathrm{C}$ & $1250^{\circ} \mathrm{C}$ & $1300^{\circ} \mathrm{C}$ & $1200^{\circ} \mathrm{C}$ & $1250^{\circ} \mathrm{C}$ & $1300^{\circ} \mathrm{C}$ & $1200^{\circ} \mathrm{C}$ & $1250^{\circ} \mathrm{C}$ & $1300^{\circ} \mathrm{C}$ \\
\hline 1 & $9.0 \pm 0.5$ & $10.8 \pm 0.6$ & $21.0 \pm 0.4$ & $12.2 \pm 4.0$ & $11.0 \pm 1.5$ & $4.2 \pm 2.2$ & $5.8 \pm 1.7$ & $5 \pm 0.7$ & $2.4 \pm 1.3$ & 18.0 & 21.2 & Crack \\
\hline 2 & $6.6 \pm 0.4$ & $9.8 \pm 0.4$ & $19.8 \pm 0.7$ & $35.1 \pm 3.4$ & $21.8 \pm 1.8$ & $11.6 \pm 2.5$ & $16.8 \pm 1.7$ & $9.2 \pm 0.8$ & $5.3 \pm 1.1$ & 21.3 & 22.9 & 46.5 \\
\hline 3 & $9.3 \pm 0.8$ & $12.4 \pm 1.1$ & $22.9 \pm 0.7$ & $35.0 \pm 1.2$ & $18.9 \pm 1.0$ & $6.3 \pm 1.7$ & $17.8 \pm 1.0$ & $7.2 \pm 0.6$ & $2.9 \pm 0.8$ & 21.0 & 22.0 & 42.7 \\
\hline 4 & $8.2 \pm 0.6$ & $11.8 \pm 0.4$ & $12.9 \pm 0.5$ & $25.6 \pm 1.7$ & $3.6 \pm 0.4$ & $8.9 \pm 1.4$ & $11.9 \pm 0.7$ & $1.8 \pm 0.8$ & $4.0 \pm 0.7$ & 27.6 & 36.1 & 42.1 \\
\hline 5 & $6.8 \pm 0.5$ & $10.4 \pm 0.8$ & $20.5 \pm 0.4$ & $31.9 \pm 1.2$ & $11.2 \pm 2.7$ & $2.8 \pm 0.6$ & $15.5 \pm 0.5$ & $5.3 \pm 1.3$ & $0.9 \pm 0.5$ & 29.0 & 41.5 & 46.3 \\
\hline 6 & $5.3 \pm 0.4$ & $11.4 \pm 0.7$ & $14.7 \pm 0.5$ & $37.0 \pm 1.8$ & $5.7 \pm 1.5$ & $2.2 \pm 0.4$ & $18.3 \pm 0.4$ & $2.8 \pm 0.7$ & $0.9 \pm 0.1$ & 27.7 & 33.1 & 35.8 \\
\hline 7 & $4.9 \pm 0.9$ & $10.4 \pm 1.2$ & $20.1 \pm 0.5$ & $20.3 \pm 3.3$ & $3.8 \pm 2.2$ & $4.6 \pm 1.8$ & $8.5 \pm 2.9$ & $4.2 \pm 1.0$ & $3.2 \pm 0.8$ & 24.5 & 25.9 & 35.0 \\
\hline 8 & $2.7 \pm 0.8$ & $5.2 \pm 0.6$ & $20.7 \pm 1.1$ & $42.1 \pm 0.9$ & $26.1 \pm 1.5$ & $4.5 \pm 0.6$ & $22.2 \pm 0.7$ & $13.9 \pm 1.0$ & $2.2 \pm 0.2$ & 30.4 & 31.2 & 58.7 \\
\hline 9 & $2.4 \pm 0.7$ & $5.1 \pm 0.4$ & $21.2 \pm 0.4$ & $43.3 \pm 1.7$ & $14.3 \pm 1.3$ & $12.5 \pm 0.8$ & $22.8 \pm 1.5$ & $7.3 \pm 0.6$ & $6.2 \pm 0.3$ & 30.1 & 41.6 & 56.0 \\
\hline 10 & $7.6 \pm 0.5$ & $10.3 \pm 0.2$ & $21.4 \pm 0.1$ & $25.7 \pm 0.1$ & $22.8 \pm 3.4$ & No data & $12.1 \pm 0.1$ & $9.0 \pm 2.1$ & No data & 19.8 & 14.5 & melt \\
\hline
\end{tabular}




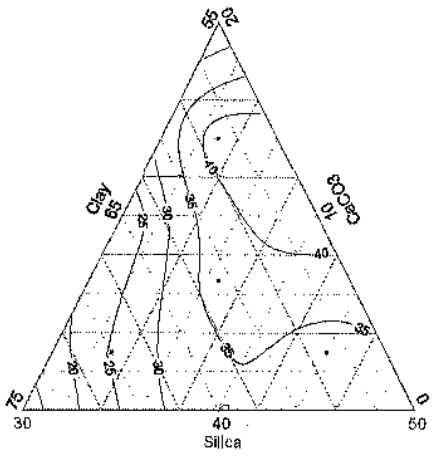

(a) $1200^{\circ} \mathrm{C}$

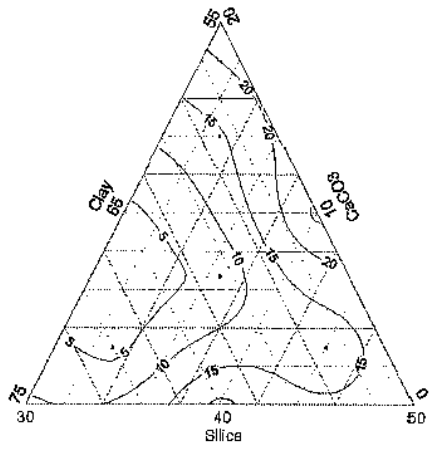

(b) $1250^{\circ} \mathrm{C}$

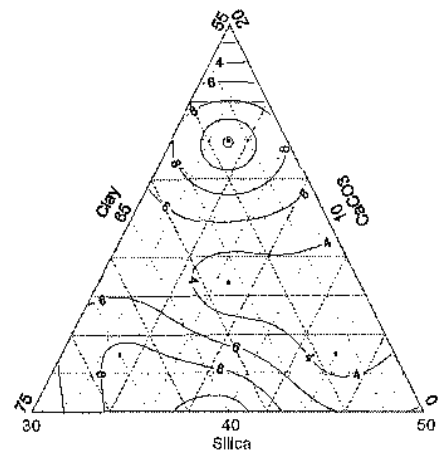

(c) $1300^{\circ} \mathrm{C}$

Figure 2 Average porosity (\%) after firing at temperatures (a) 1200 , (b) 1250 and (c) $1300^{\circ} \mathrm{C}$

firing temperatures. The plots show that the porosity decreases from the maximum $43.3 \%$ (mixture formula 9 at $1200^{\circ} \mathrm{C}$; Figure $2(\mathrm{a})$ ) to $26.1 \%$ (mixture formula 8 at $1250^{\circ} \mathrm{C}$; Figure $2(\mathrm{~b})$ ) to the minimum $2.2 \%$ (mixture formula 6 at $1300^{\circ} \mathrm{C}$; Figure $\left.2(\mathrm{c})\right)$ when the firing temperature increase from 1200 to $1300^{\circ} \mathrm{C}$. Figure 3 shows the contour plots for the water absorption in which its effects are similar to the porosity. Figure 4 shows the plots for the bending strength at different firing temperatures. At firing temperatures of 1200 and $1300^{\circ} \mathrm{C}$, the bending strengths reach maximum 30.4 and $58.7 \mathrm{MPa}$ at the mixture formula 8 (Figures 4(a), 4(c)) while shifting to the maximum 41.6 $\mathrm{MPa}$ at $1250^{\circ} \mathrm{C}$ towards the larger proportion of inert silica or carbonate while lesser clay content (Figure 4(b)).

\subsection{The Selected Mixtures for Production of Porous Ceramic Membrane}

Figure 5 shows the selected mixture compositions for the production of porous ceramic membrane. The firing temperature of $1200^{\circ} \mathrm{C}$ is suitable for porous ceramic production according to the results of the tests. However, lower the firing temperatures down to $1100^{\circ} \mathrm{C}$ could be interesting for further tests. The plots show the shaded area where the porosities are larger than 40\% (Figure 5(a)). In this area of mixture compositions, the linear shrinkage is $3-4 \%$ (Figure $5(\mathrm{~b})$ ) and bending strength is ca. $28-30 \mathrm{MPa}$ (Figure $5(\mathrm{c})$ ). In this ranges of mixtures, the clay, silica and calcium carbonate proportions are between $55-59 \mathrm{~g}, 32-$ $42 \mathrm{~g}$, and $8-16 \mathrm{~g}$, respectively, in $105 \mathrm{~g}$ total weight

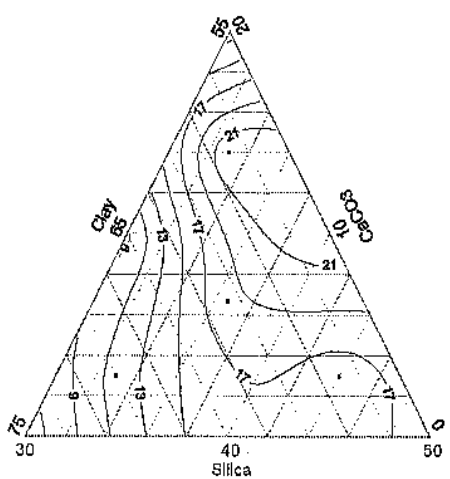

(a) $1200^{\circ} \mathrm{C}$

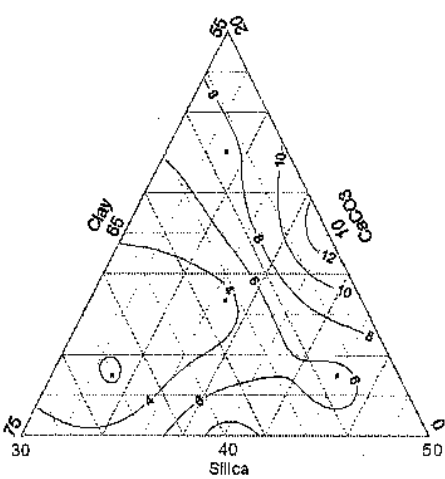

(b) $1250^{\circ} \mathrm{C}$

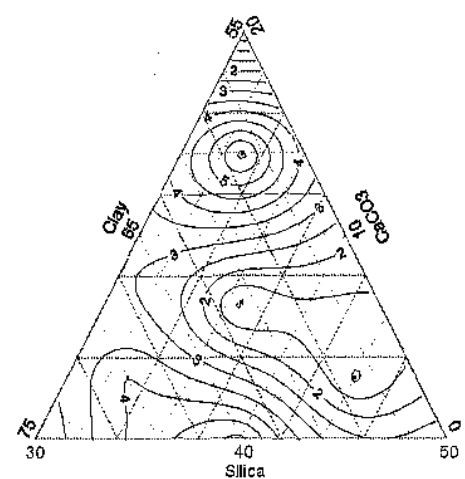

(c) $1300^{\circ} \mathrm{C}$

Figure 3 Average water absorption (\%) after firing at temperatures (a) 1200 , (b) 1250 and (c) $1300^{\circ} \mathrm{C}$ 


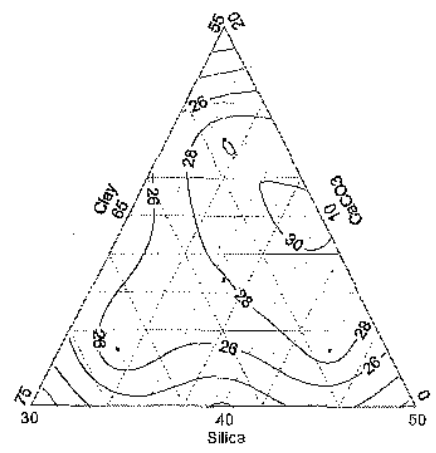

(a) $1200^{\circ} \mathrm{C}$

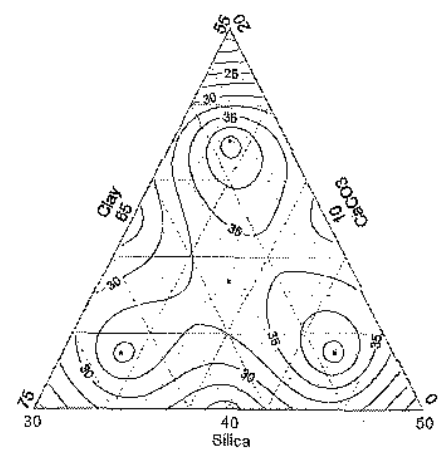

(b) $1250^{\circ} \mathrm{C}$

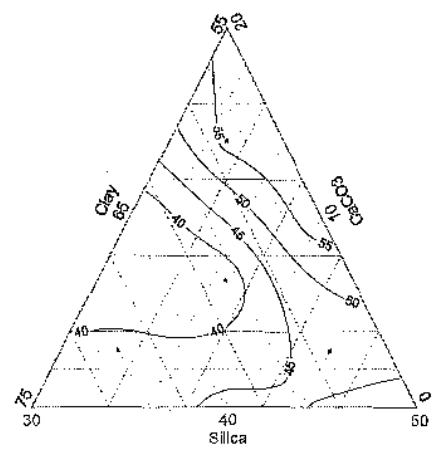

(c) $1300^{\circ} \mathrm{C}$

Figure 4 Bending strength (MPa) after firing at temperatures (a) 1200, (b) 1250 and (c) $1300^{\circ} \mathrm{C}$

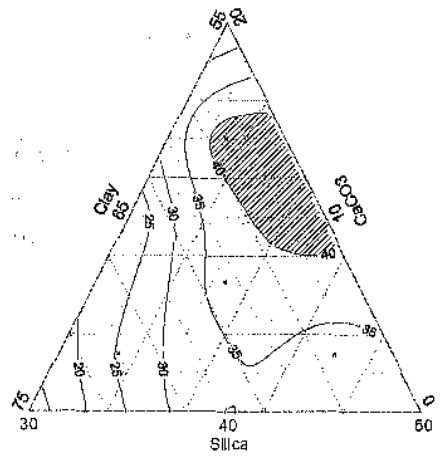

(a) Porosity (\%)

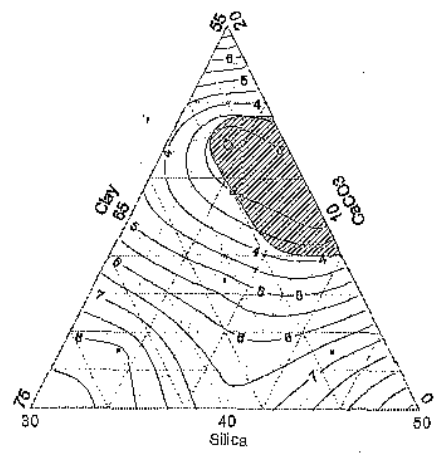

(b) Linear firing shrinkage (\%)

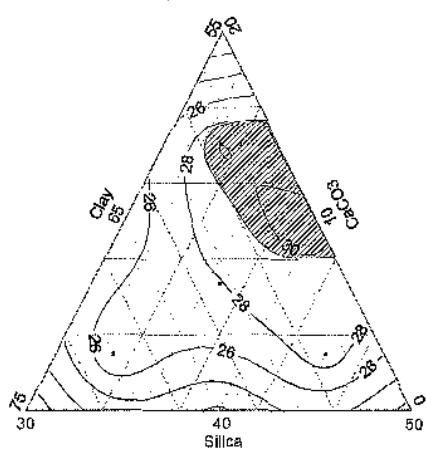

(c) Bendiang strength (MPa)

Figure 5 The mixture compositions at which (a) the porosities are above $40 \%$ (shaded area) and the correlated properties (b) firing shrinkage and (c) bending strength after firing at $1200^{\circ} \mathrm{C}$

of mixture, or weight fraction of $0.524-0.0 .562$, $0.076-0.152$, and $0.310-0.394$, respectively. An example of the selected mixture, clay : silica : calcium carbonate of $57 \mathrm{~g}: 34 \mathrm{~g}: 14 \mathrm{~g}$ could produce the porous ceramic in which its porosity is larger than $40 \%$. Figure 6 shows the SEM micrographs of the porous ceramic membrane prepared from mixture formula 8 (see Table 1). Figure 6(a) shows the cross sectional view of sample sintered at $1200^{\circ} \mathrm{C}$ that indicates the uniformly distributed open long pores over the area examined. Similar surface morphology of this sample can be seen at the top surface view (Figure 6(b)) and the bottom surface view (Figure 6(c)). The sample sintered at $1250^{\circ} \mathrm{C}$ shows the cross sectional top surface dense layer of $50 \mu \mathrm{m}$ thick (Figure 6(d)). The top surface is very dense and no pore can be observed at the same magnification $\times 1000$, unlike the samples sintered at $1200^{\circ} \mathrm{C}$ (Figure $6(\mathrm{~b})$ ). No any pore can be seen at the top surface even at the $\times 10000$ after scan over a large area (Figure 6(e)) and only one pore seen at the bottom surface at the $\times 10000$ (Figure 6(f)). The $50 \mu \mathrm{m}$ thick denser top surface layer occurred after firing at $1250^{\circ} \mathrm{C}$ is probably a result of fusion enhancements of calcium carbonate in ceramic mixture at this temperature higher than those at lower temperatures. The mode, median and mean pore sizes of this sample sintered at $1250^{\circ} \mathrm{C}$ analyzed using the mercury porosimeter are $0.40,0.40$ and $0.11 \mu \mathrm{m}$, respectively. 


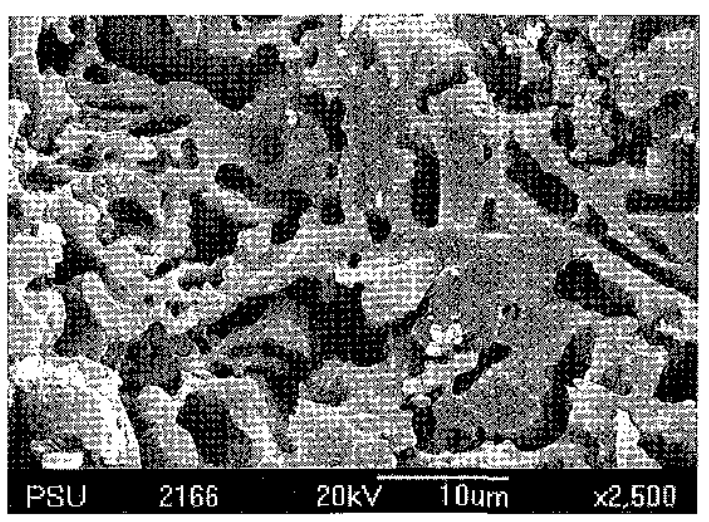

(a)

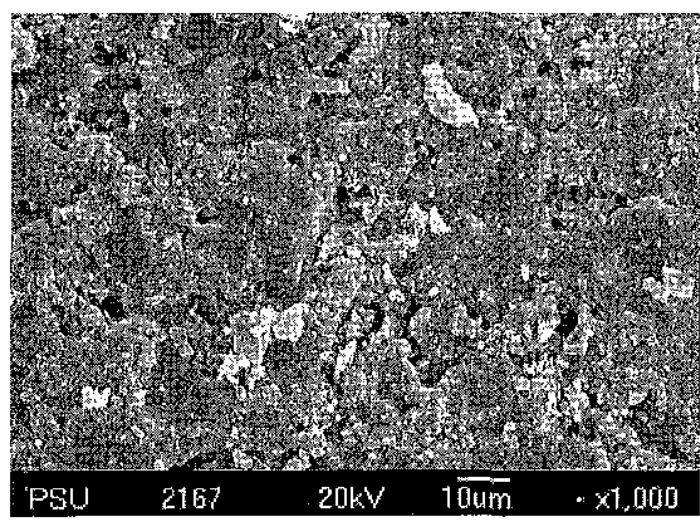

(b)

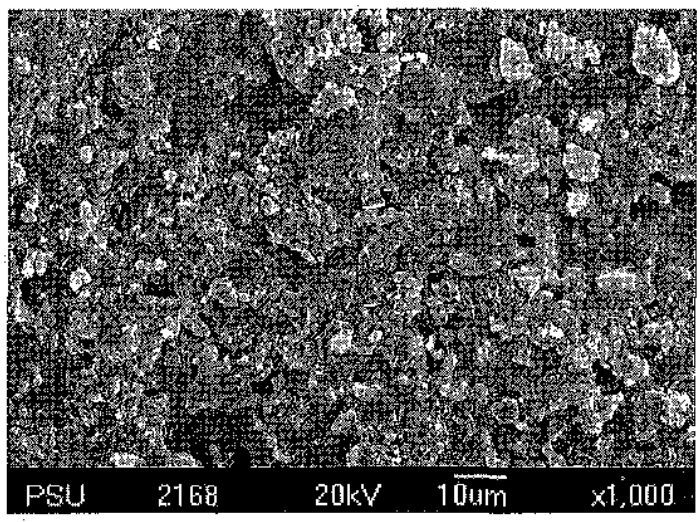

(c)

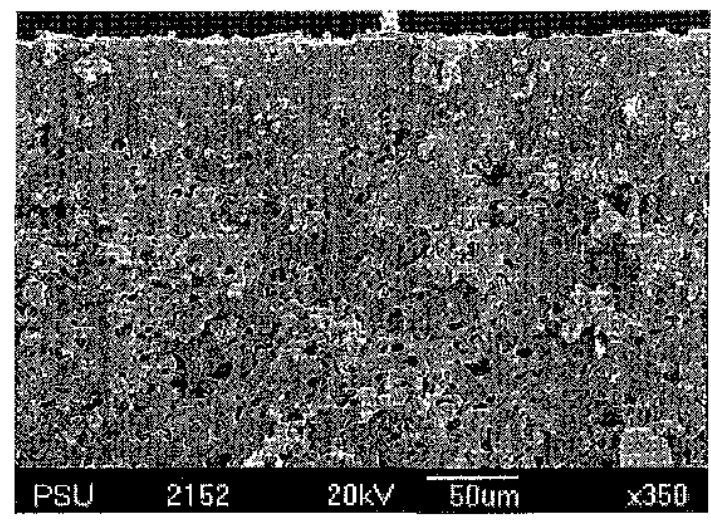

(d)

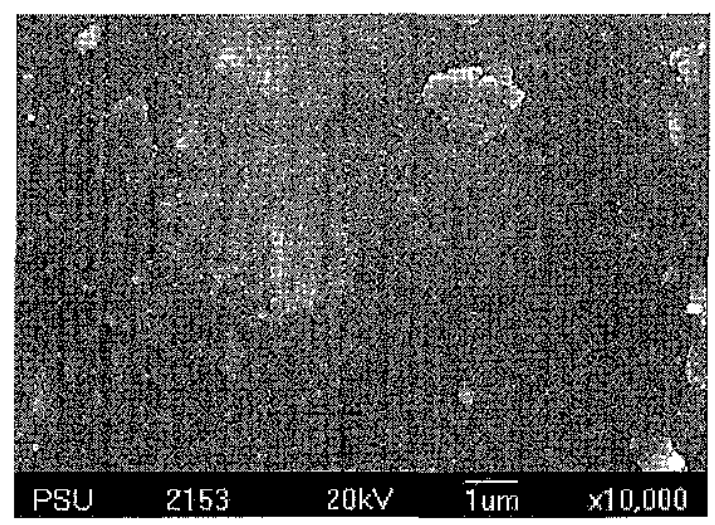

(e)

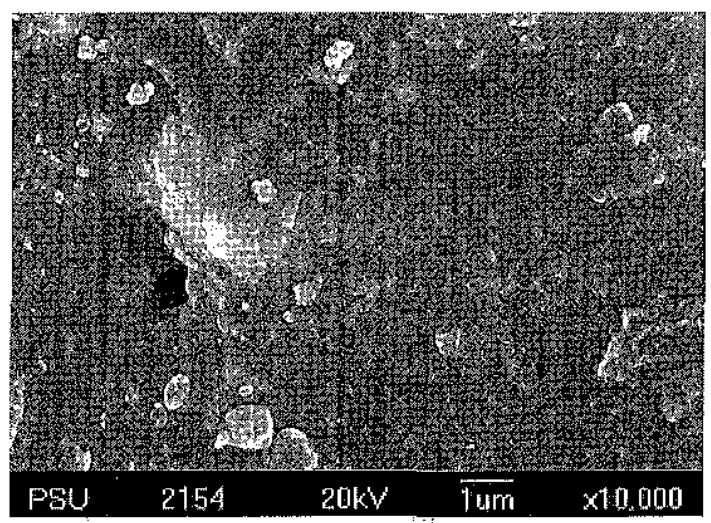

(f)

Figure 6 SEM micrographs of the sample mixtures formula 8 for (a) (b) (c) sintered at $1200^{\circ} \mathrm{C}$ and (d) (e) (f) sintered at $1250^{\circ} \mathrm{C}$. Images (a) (d) show the cross-sectional views, (b) (e) show the top or surface layer and (c) (f) show the bottom or support layer 
Table 3 Pure water flux of mixture formula 8 and 9 at the optimum firing temperature of $1200^{\circ} \mathrm{C}$

\begin{tabular}{|c|c|c|c|c|}
\hline \multirow{2}{*}{$\begin{array}{l}\text { Mixture } \\
\text { formula }\end{array}$} & \multicolumn{3}{|c|}{ Pure water flux $\left(\mathrm{L} / \mathrm{m}^{2} . h\right)$} & \multirow[b]{2}{*}{$120 \mathrm{kPa}$} \\
\hline & $30 \mathrm{kPa}$ & $60 \mathrm{kPa}$ & $90 \mathrm{kPa}$ & \\
\hline 8 & $31.0 \pm 2.7$ & $101.7 \pm 13.2$ & $180.8 \pm 5.3$ & $244.8 \pm 60.1$ \\
\hline 9 & $52.4 \pm 11.0$ & $145.6 \pm 2.0$ & $265.7 \pm 15.8$ & $368.8 \pm 51.6$ \\
\hline
\end{tabular}

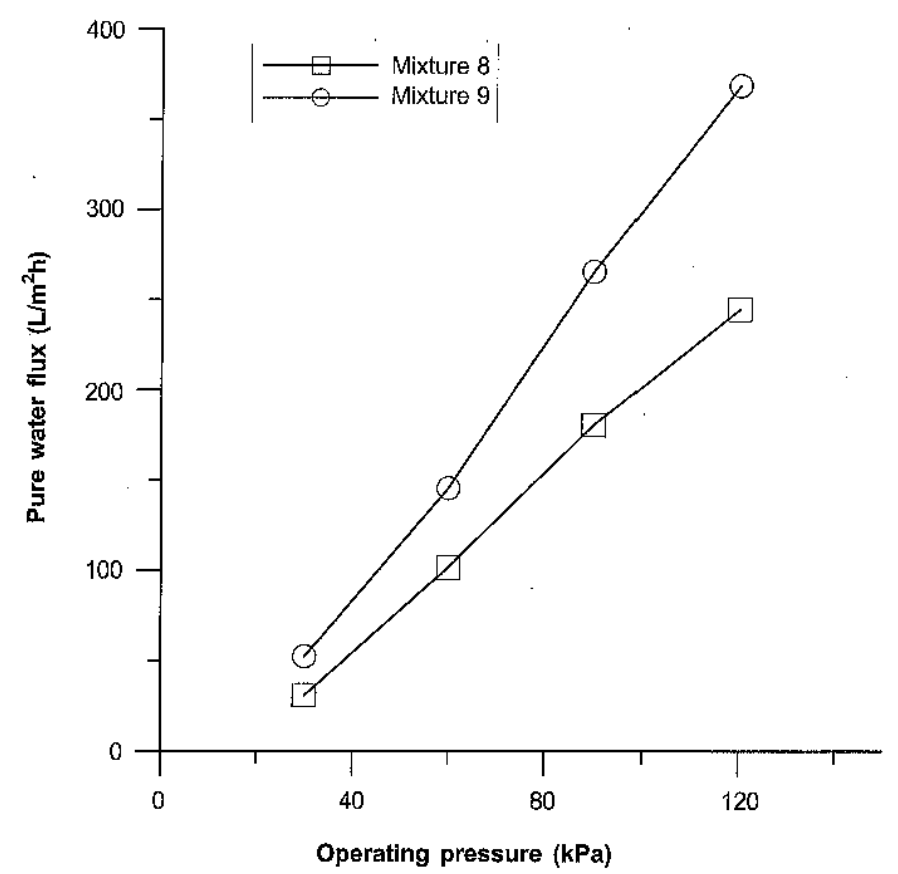

Figure 7 Pure water flux versus pressure for mixture formula 8 and 9 at the optimum firing temperature of $1200^{\circ} \mathrm{C}$

\subsection{Pure Water Flux Test}

The pure water flux (PWF) is measured under steady-state flow using the equation, $J_{W}=Q / A \Delta T$ (1), Where, $J_{W}$ is the water flux $\left(\mathrm{L} \mathrm{m}^{-2} \mathrm{~h}^{-1}\right), \mathrm{Q}$ is the quantity of water permeated (litre) during the sampling time $\Delta T$ (hour) and $A$ is the membrane area $\left(\mathrm{m}^{2}\right)$.

The PWF is performed only at the best mixtures (formula 8 and 9) which have a high porosity. Table 3 and Figure 7 show the PWF at different operating pressures of $30-120 \mathrm{kPa}$. Result clearly indicates a linearly dependence of the pure water fluxes on pressures. Samples prepared from mixture formula 9 sintered at $1200^{\circ} \mathrm{C}$ have a higher PWF (52.4-368.8 L/m $\mathrm{m}^{2} . \mathrm{h}$ ) than those of mixture formula $8\left(31.0-244.8 \mathrm{~L} / \mathrm{m}^{2} \cdot \mathrm{h}\right)$ at the operating pressures ranged $30-120 \mathrm{kPa}$, indicating that the ternary mixture compositions nearby the formula 9 are the best for porous ceramic production using Ranong kaolin.

\subsection{CONCLUSIONS}

The design of mixture experiments and the use of ternary mixture diagram and contour plot of the selected properties superimposed enabled the interpretation of relating properties with composition, which can then be used to select the best combination of three given raw materials (Ranong kaolin or any clay mixture, calcium carbonate and quartz) to produce a ceramic membrane with specified properties under constant processing 
conditions. Furthermore, the use of intersecting properties values shows that, for the particular raw materials of interests, there is a rather forgiving composition range within which it is possible to specify the values of two different properties.

\section{ACKNOWLEDGEMENTS}

The authors appreciate the financial support from the Prince of Songkla University, and are thankful to Mr.Supol Rathnarathorn the owner of Ratthnarathorn Mine, Ranong province, southern Thailand for providing the raw materials used.

\section{REFERENCES}

[1] Babaluo, A.A., M. Kokabi, M. Manteghian, and R. Sarraf-Mamoory. 2004. A Modified Model for Alumina Membranes Formed by Gel-casting Followed by Dip-coating. J. Eur. Ceram. Soc, 24: 3779-3787.

[2] Lyckfeldt, O. and J.M.F. Fereira. 1998. Processing of Porous Ceramics by Starch Consolidation. J. Eur. Ceram. Soc. 18: 131140.

[3] Das, N. and H.S. Maiti. 1998. Formatation of Pore Structure in Tape-cast Alumina Membranes - Effects of Binder Content and Firing Temperature. J. Mem. Sci. 140: 205212.

[4] Ahmad, A.L., N.F. Idrus and M.R. Othman. 2005. Preparation of Perovskite Alumina Ceramic Membrane using Sol-gel Method. J. Mem. Sci. 262: 129-137.
[5] Ayari, F., E. Srasra and M. Trabelsi-Ayadi, 2005. Characterization of Bentonitic Clays and their use Adsorbent. Desalination. 185: 391-397.

[6] He, C., E. Makovicky and B. Osbæek. 2000. Thermal Stability and Pozzolanic Activity of Raw and Calcined Mixed-layer Mica/ smectite. Appl. Clay Sci. 17: 141-161.

[7] Khemakhem, S., R.B. Amar and A. Larbot, 2007. Synthesis and Characterization of a New Inorganic Ltrafiltration Membrane Composed Entirely of Tunisian Natural Illite Clay. Desalination. 206: 210-214.

[8] Le Van Mao, R., E. Rutinduka, C. Detellier, P. Gougay, V. Hascoet, S. Tavakoliyan, S. V. Hoa and T. Matsura. 1999. Mechanical and Pore Characteristics of Zeolite Composite Membrane. J. Mater. Chem. 9: 783-788.

[9] Shukla, A. and A. Kumar. 2005. Characterization of Chemically Modified Zeoliteclay Composite Membranes using Separation of Trivalent Cations. Sepa. Puri. Techn. 41: 83-89.

[10] ASTM Standard C326-03. Standard Test Method for Drying and Firing Shrinkages of Ceramic Whiteware Clays. ASTM International, West Conshohocken, PA, www.astm.org.

[11] ASTM C373-88 2006. Standard Test Method for Water Absorption, Bulk Density, Apparent Porosity, and Apparent Specific Gravity of Fired Whiteware Products. ASTM International, West Conshohocken, PA, www.astm.org. 